\title{
The impact of students and curriculum on self-study during clinical training in medical school: a multilevel approach
}

\author{
J. Barbosa ${ }^{1 *}$ (D) A. Silva ${ }^{2}$, M. A. Ferreira ${ }^{3}$ and M. Severo ${ }^{3}$
}

\begin{abstract}
Background: In higher education, the focus has shifted from the acquisition of knowledge to learning objectives and skills. This means that, the majority of student learning time is spent independently working outside the classroom. Students take an active role in setting goals, deciding how to achieve them, and planning individual study time. Although extensive research has recognized the importance of curriculum and students' characteristics in time devoted to self-study, it is still unclear to what extent these variables affect time to study. Due to the growing reliance on self-directed learning in medical education, and in an attempt to elucidate this issue, this research aims to evaluate self-study time during clinical training and assess whether this is more influenced by the student or the curriculum.

Methods: A questionnaire was given to 1220 medical students (43.3\% of the enrolled students). The students were asked to indicate the average number of study hours per week beyond the time allocated to classes for each clerkship (rotation) attended. Variation and generalizability of students' self-study were estimated using linear mixed models.
\end{abstract}

Results: Findings showed that the intrinsic differences within students were a greater source of variation in self-study time than differences within clerkships (56.0\% vs. 6.9\%). If the amount of self-study dedicated to an individual clerkship is to be determined, at least 32 students are needed to achieve acceptable reliability. However, this data with two clerkships per student can used to retrospectively measure the self-study reported by students in clinical training.

Conclusions: The findings suggest that, both, curriculum and student characteristics influence self-study in undergraduate clinical training. Indeed, students' characteristics play a significant role in time devoted to study. Further research should be undertaken to investigate students' characteristics that may predict self-study during undergraduate medical training.

Keywords: Clinical training, Curriculum design, Medical students, Self-directed learning, Self-study

\section{Background}

Workload is measured as the number of contact hours (timetabled study hours, i.e. class attendance) plus the time spent on self-study (non-timetabled study hours, i.e. time spent outside the classroom for learning purposes, either for class assignments, group work, or studying for an assessment) [1]. As contact hours can be

\footnotetext{
*Correspondence: joselina@med.up.pt

'Department of Simulation and Medical Education, Faculty of Medicine of the University of Porto, Al. Prof. Hernâni Monteiro, 4200-319 Porto, Portugal

Full list of author information is available at the end of the article
}

easily identified and account for approximately one-third of the total working time [2], it remains important to find out the time students devote to self-study. In higher education, the focus has shifted from the acquisition of knowledge to learning objectives and skills. The majority of student learning time is spent independently working outside the classroom. This educational approach emphasizes the active role of students in setting goals, deciding how they will achieve them, and scheduling and planning one's study time [3]. Consequently, to a 
large extent, it depends on students' time allocations for self-study.

For many students the amount of work required is the most important factor affecting their involvement with a course [4]. To learn effectively, it is essential that students are given sufficient time for processing their learning [5]. However, there is typically no attempt to enforce the hours of self-study, and it is simply assumed that these will take place in the program. Within this framework, monitoring student's self-study and emphasizing its importance is key to the learning process.

Factors found to be influencing time to study have been explored in several studies. Published research recognizes that curriculum characteristics affect the amount of time students devote to study. For example, factors such as difficulty of the scientific area, field of study, number of assessments and different supervised learning environments are considered to be associated with time devoted to self-study [6-11]. Conversely, students differ in the time they need to achieve learning outcomes, which can be explained by individual characteristics and learning styles [6, 12-16]. For medical students, self-learning experiences and time for self-study will allow them to develop skills for lifelong learning. In clinical training where the main concern is patient care, students are faced with less structured styles of teaching and learning $[17,18]$. The tasks to be learned require simultaneous integration of multiple sets of knowledge, skills and behaviors at a specific time and place [19]. The strategic selection and application of learning skills is crucial to the adaptation of students to this challenging learning environment. Some students find the environment motivating and exciting, whereas others become stressed and perceive a high workload.

Although extensive research has recognized the importance of curriculum and individual differences in time devoted to self-study, it is still unclear to what extent these variables affect time to study [20]. Given the responsibility of schools to develop adequate curricula for achieving learning objectives, it is important to discriminate the relative contributions from students and curriculum to the time devoted to self-study. To our knowledge, no study has explored this issue within clinical training. The present research explores, for the first time, the variation in time devoted to self-study during clinical training as accounted for by student and curriculum factors. We also aimed to use variance estimates to determine the optimal number of clerkships needed to estimate students' self-study and, in turn, the optimal number of students needed to estimate each clerkship's self-study. These figures are needed because resources are limited, and in medical education it is not always easy to get volunteer students to answer questionnaires [21]. The results may inform decisions about how best to allocate self-study across clerkships and guide teachers about where to direct their efforts to minimize individual differences and enhance the effectiveness of self-study.

\section{Methods}

\section{Educational context (curriculum outline)}

This study was conducted in a public medical school in North of Portugal, with a curriculum that complies with the Bologna Process of 2007/2008. One ECTS (European Credit Transfer and Accumulation System) is defined as a total of $27 \mathrm{~h}$, and a full year of academic study would yield 60 ECTS, representing a workload of $1620 \mathrm{~h}$. Timetabled study-related activities constitute $25-35 \%$ of the total number of working hours. The undergraduate medical course lasts for 6 years consisting of basic/pre-clinical work (first 3 years) and a clinical stage following that. The first 3 years cover 32 semester disciplines of basic and pre-clinical sciences. The last 3 years cover 25 clerkships of clinical practice attended one at a time throughout the academic year. In addition, students develop a research project and take an optional course (listed in Appendix).

\section{Study design}

As part of a program evaluation at the end of the assessment period, students in clinical years completed a questionnaire to evaluate each clerkship. The questionnaire comprised one item about time devoted to self-study per week: How many hours did you spend on average per week on self-study (study outside the hospital for learning purposes whether it is for class assignments, group work, or studying for an assessment) throughout the academic year?

The data comprised input for the 25 clerkships assessed in four consecutive academic years (cohorts 2008/2009 till 2011/2012). A total of 1220 students of the 2820 enrolled (43.3\%) participated in the study (408, 276 and 536 from 4th, 5th and 6th years, respectively). Each student answered based on all their clerkships of the respective curricular year: nine clerkships in year 4 , ten in year 5 , and six in year 6 (Median per curricular and academic year $=69$; Percentile $25-75=52-141)$.

\section{Definition of exposures/outcomes}

Our outcome was the self-study hours per week devoted to each clerkship. Self-study time was expressed in hours/week. Our main exposures were clerkships and students. We also considered if self-study hours allocated in our curriculum and academic year explained variability of our main exposures. The selfstudy hours allocated in our curriculum were defined by ECTS $27 * \mathrm{SH}$ and were scaled by subtracting the mean of allocated study hours of sample: 24.9, where $\mathrm{SH}$ is the percentage of study hours allocated in our curriculum to self-study hours. 


\section{Statistical analysis}

Differences between self-study hours devoted to each clerkship were described with mean and standarddeviation (SD).

Linear mixed effects models were used to estimate the relative contribution that clerkships and students made to the variation in self-study time. The variables, selfstudy hours allocated in our curriculum and academic year, were entered as fixed effects of the linear mixed effects models. To account for intra-students and intraclerkships variance in the data we performed the multilevel analysis using student-level and clerkship-level, as random effects of our model.

Three models were constructed. The first model, an empty or zero model, was built only with the intercept as a fixed effect and random effects for clerkships and students. The second model contained the self-study hours allocated in our curriculum/week as the fixed effect. The third model additionally included the academic year. To compare the fit between models, we used the log likelihood ratio test, the Bayesian information criteria, and Akaike information criterion.

The fixed effects were expressed as regression coefficients and corresponding 95\% confidence intervals (CI). The random effects (measures of variation) were expressed as Intraclass Correlation Coefficient (ICC) and proportional change in variance (PCV). The ICC provides an estimate of the proportion of total variance related to students or clerkships. The PCV assessed the amount of variance explained. The PCV was calculated as:

$$
P C V=\frac{V_{0}-V_{i}}{V_{0}} \times 100 \text {, }
$$

where $V_{0}$ is the estimate of the initial (null) variance of empty model and $V_{i}$ is the variance of model adjusted for curriculum variables added to empty model [22].

The data from the variance components where then used in a decision study (D study) to estimate the optimal clerkships needed to estimate students' self-study and the optimal students needed to estimate each clerkship's self-study. For this, we required a reliability of 0.7. Statistical analyses were performed using $\mathrm{R}$ software version 2.14.1. For all comparisons, statistical significance was set at $\alpha$ level $\leq 0.05$.

\section{Results}

\section{Curriculum and student effect on self-study hours}

We observed differences between the average self-study hours devoted to each clerkship. The least amount of time spent was $5.1 \mathrm{~h}$ per week $(\mathrm{SD}=5.0)$ at Bioethics and Deontology in fourth curricular year. The greatest amount of time spent on self-study was 19.2 ( $\mathrm{SD}=12.4$ ) hours per week in the Medicine rotation of 5 th year (Table 1).

Figure 1 shows the average self-study per week by academic year and the average clerkship's self-study per
Table 1 Number of hours spent per week on self-study for each clerkship

\begin{tabular}{lll}
\hline Year & Clerkship & Mean (standard-deviation) \\
\hline 4th & Bioethics and Deontology & $5.1(5.0)$ \\
& Dermatology and Venereology & $13.0(11.4)$ \\
& Medicine I & $14.8(12.6)$ \\
& Neurology and Neurosurgery & $9.9(8.0)$ \\
Orthopaedics and Traumatology & $9.1(7.1)$ \\
Otorhinolaryngology & $7.5(6.6)$ \\
& Radiology & $12.2(10)$ \\
Surgery I & $13.1(11.2)$ \\
Therapeutic & $11.3(9.3)$ \\
5th & $8.1(7.1)$ \\
& Anesthesia & $8.3(6.7)$ \\
& Legal Medicine & $19.2(12.4)$ \\
Medicine II & $10.2(8.1)$ \\
Opthalmology & $12.6(10.7)$ \\
Obstetrics and Gynecology & $16.4(10.5)$ \\
Pathological Anatomy & $12.7(10.2)$ \\
Pediatrics I & $10.2(7.7)$ \\
Psychiatry I & $12.0(10.2)$ \\
Surgery II & $12.0(9.4)$ \\
Urology & $10.1(10.8)$ \\
Community Medicine & $13.6(11.9)$ \\
Medicine II & $8.3(9.5)$ \\
Obstetrics & $8.0(9.2)$ \\
Pediatrics II & $9.2(10)$ \\
Psychiatry II & $9.4(8.9)$ \\
Surgery III &
\end{tabular}

week by academic year. There is greater individual variation in time spent on self-study by students than by clerkship.

Table 2 presents the results of the mixed linear models, with time devoted to self-study as the outcome. Students spent an average of 9.8 (95\% Confidence Interval: 9.0-11.2) hours per week in each clerkship in clinical training. For each hour of increase in the allocated self-study hours, the reported self-study hours increased 0.2 (95\% Confidence Interval: $0.1-0.3)$, i.e., for every hour of allocated selfstudy, students dedicated an additional $12 \mathrm{~min}$ to self-study. A non-significant effect for the academic year (Model 3) was observed.

In Model 1 only $6.9 \%$ of variance of the total observed self-study hours can be ascribed to differences within clerkships. In contrast differences within students accounted for $56.1 \%$. After adjusting for allocated selfstudy hours (Model 2) the variance within clerkships and within students remained the same. The residual variance between clerkships and students accounted for 


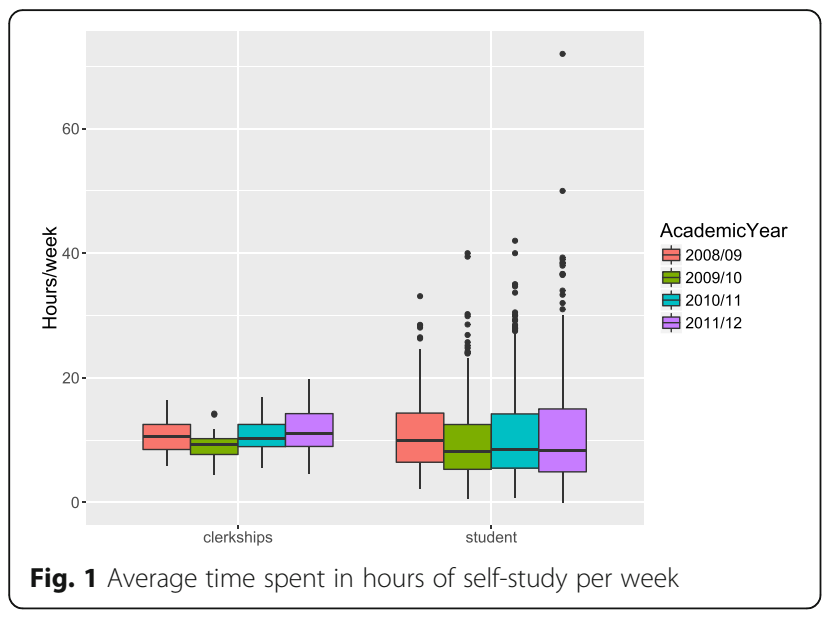

Table 2 Fixed and random effects in self-study hours

\begin{tabular}{|c|c|c|c|}
\hline & Model 1 & Model 2 & Model 3 \\
\hline Source of Variation & $\begin{array}{l}\text { Coefficient } \\
(95 \% \mathrm{Cl})\end{array}$ & $\begin{array}{l}\text { Coefficient } \\
(95 \% \mathrm{Cl})\end{array}$ & $\begin{array}{l}\text { Coefficient } \\
(95 \% \mathrm{Cl})\end{array}$ \\
\hline \multicolumn{4}{|l|}{ Fixed effects } \\
\hline (Intercept) & $9.8(9.0 ; 11.2)$ & $9.8(8.9 ; 11.0)$ & $10.6(9.1 ; 12.2)$ \\
\hline $\begin{array}{l}\text { Allocated Self-Study } \\
\text { Hours }\end{array}$ & - & $0.2(0.1 ; 0.3)$ & $0.2(0.1 ; 0.3)$ \\
\hline Academic year & - & - & \\
\hline $2007 / 2008$ & & & Reference \\
\hline 2008/2009 & & & $-1.5(-2.7 ;-0.3)$ \\
\hline 2009/2010 & & & $-0.8(-1.7 ; 0.7)$ \\
\hline $2010 / 2011$ & & & $-0.4(-1.1 ; 1.2)$ \\
\hline \multicolumn{4}{|l|}{ Random effects } \\
\hline \multicolumn{4}{|l|}{ Clerkship } \\
\hline Variance & 7.3 & 7.3 & 7.3 \\
\hline PCV (\%) & Reference & 0.0 & 0.0 \\
\hline ICC (\%) & 6.9 & 6.9 & 6.9 \\
\hline \multicolumn{4}{|l|}{ Student } \\
\hline Variance & 59.3 & 59.2 & 59.1 \\
\hline PCV (\%) & Reference & 0.2 & 0.3 \\
\hline ICC (\%) & 56.1 & 56.0 & 55.9 \\
\hline $\begin{array}{l}\text { Residual variance } \\
\text { (Clerkship*Student) }\end{array}$ & 39.2 & 39.2 & 39.2 \\
\hline$p$ value $^{+}$ & - & $<0.001$ & 0.268 \\
\hline AIC & 57,663 & 57,654 & 57,656 \\
\hline $\mathrm{BIC}$ & 57,691 & 57,689 & 57,712 \\
\hline $\log L$ & $-28,827$ & $-28,822$ & $-28,820$ \\
\hline
\end{tabular}

Abbreviations: $P C V$ proportional change in variance, $\mathrm{Cl}$ confidence interval, ICC intraclass correlation coefficient, AIC Akaike information criterion, BIC Bayesian information criteria, $\log L$ Log likelihood

${ }^{+}$Likelihood ratio test
$39.2(37.1 \%)$ of the variance of total observed self-study hours (Fig. 2).

\section{Reliability}

Figure 3 shows the progression of the reliability coefficients in terms of the number of clerkships needed to determine students' self-study, and the number of students needed to discern self-study in each clerkship in clinical training. If we accept a level of 0.7 on the grounds of feasibility, then 32 students would be needed to achieve reliability for the clerkship. Based on the available estimated variance components, a reliability of at least 0.70 requires two clerkships to achieve reliability for the student.

\section{Discussion}

Due to the growing reliance on self-directed learning in medical education, this study aimed to explore the extent to which students and curriculum influence the time devoted to self-study within an undergraduate clinical training program. The first important finding was that, as expected, time devoted to self-study in clinical training is related to the curriculum and student characteristics. Estimated variance attributable to differences among students (55.9\%) is about eight times as large as the $6.9 \%$ estimated variance attributable to differences among clerkships. We may be underestimating the variance explained by clerkships because only differences between clerkships were evaluated and not differences between learning environments or supervisors. However, differences between learning environments and supervisors would never exceed the variance explained by students because clerkship student interaction variance was 39.2 (37.1\%). This suggests that students' characteristics are a greater source of variability in self-study than clerkships in undergraduate clinical training. Clearly, this phenomenon is affected

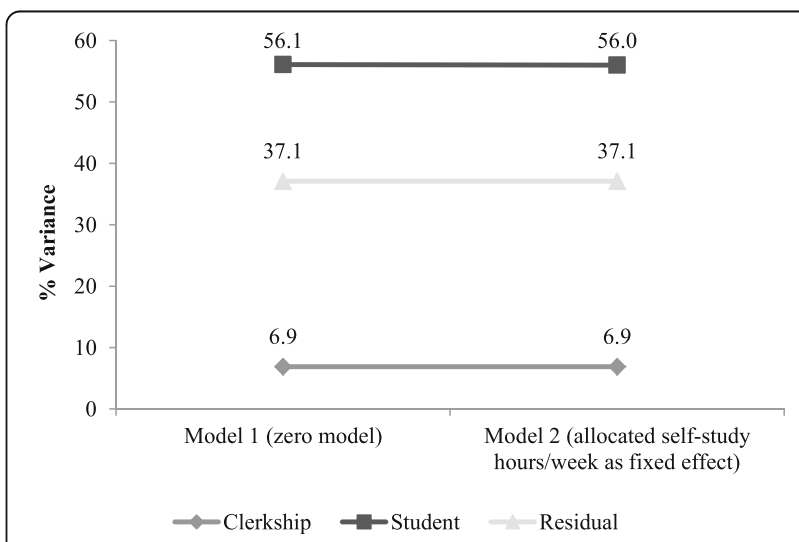

Fig. 2 Variability explained by clerkships and students in the self-study hours 

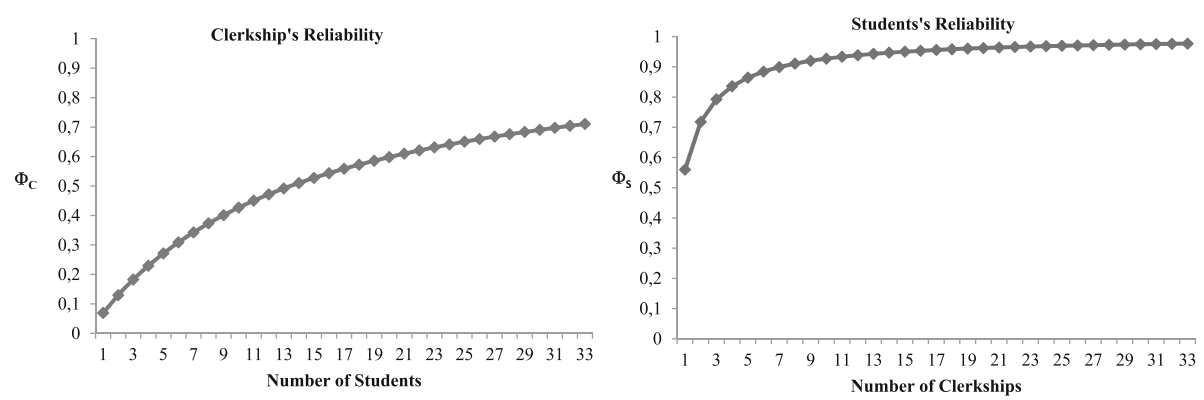

Fig. 3 The clerkship's reliability by the number of students and student's reliability by the number of clerkships

by the number of students needed to obtain a reliable estimate of self-study for each clerkship. If we want to know the amount of self-study dedicated to an individual clerkship, we need at least 32 students to achieve acceptable reliability. However, data with two clerkships per student is useful for measuring retrospectively reported self-study in clinical training (D study interpretation).

These findings support Van der Huk et al. who showed large individual variation in the time spent on self-study for each module in a problem-based curriculum [6]. It is encouraging to compare our figures with those of Snelling et al. because together they suggest that effective self-study is not just a matter of time available, but depends on students taking responsibility for their own learning [2]. Beyond timetabled training sessions, students undertake self-study with textbooks, examination guidelines, scientific articles, the Internet, videos, previous OSCEs and practice skill training [20]. Based on our results it would be important to look for students' characteristics that may predict study time investment in the clinical years. For instance, Wilkinson et al. found that students who have a desire to achieve and who are well organized and committed to their career choice as a doctor will devote more time to study [14]. Students who lacked confidence and had inefficient study habits were also noted to study more [14]. In contrast, students who procrastinated used only a proportion of the self-study time available [11]. Teachers should focus their efforts on supporting students to acquire self-learning skills and guide them to efficiently use self-study time [23].

Our results showed that, in general, medical students appear to be spending $9.8 \mathrm{~h} /$ week in self-study in clinical training. This constitutes half of the selfstudy allocated in the curriculum. Previous studies have assessed the study time spent on activities of clinical training based on student report at the end of an assessment period. Dolmans et al. evaluated the time students spend in different study activities over the course of eight clinical rotations [24]. They found that students devoted $8 \mathrm{~h}$ per week to self-study, slightly less than our results. Similar to our findings, Medicine and Pediatric rotations involved more selfstudy time. In an anesthesiology residence program, the average time spent in self-study was $8 \mathrm{~h} /$ week [25], further supporting our results. However, these findings differ from some published studies that record student's study time over relative short periods with weekday hours spent on each activity. A project designed to describe and analyze a typical student week in clinical practice showed that students studied for about $60 \mathrm{~h}$ per week with self-study comprising 26 of these hours [26]. Another study of final year medical students also evaluated a typical week in three clerkships. Median total time spent on learning activities was $43.7 \mathrm{~h}$, and of this about 6.2 were allocated to self-study.

The analysis of ECTS undertaken here, has extended our knowledge of how students distribute their effort in clinical training. There were specific courses for which self-study was generally more demanding. Results showed that as allocated self-study hours increase, the time spent on self-study also increases. For each hour of allocated study, students engaged in a further 12 min of self-study. As shown originally by Jansen et al. [10], time management is easier to control in the clinical years when students have one clinical module at a time.

Finally, a number of important limitations need to be considered. Reliability may be compromised when results are based on subjective information. However, the reduced variation in time devoted to study when using the mixed model with the academic year (cohorts 2008/2009-2011/2012) demonstrates a pattern over time and supports reliability of the results. Furthermore, preliminary studies shown that this method provides a reliable indicator of the time spent on individual study [27, 28]. A second and obvious limitation is that the present findings may not be generalizable to non-medical schools. 


\section{Conclusion}

In summary, the findings of this study suggest that, both, curriculum and students characteristics appear to be related to time devoted to self-study. It is proposed therefore that further research should be undertaken to investigate the students' characteristics that may predict self-study during undergraduate medical training.

\section{Appendix}

Table 3 Clinical Practice per curricular year

\begin{tabular}{|c|c|}
\hline Curricular Year & Credits (ECTS) \\
\hline \multicolumn{2}{|l|}{ Year IV } \\
\hline Bioethics and Deontology & 3 \\
\hline Dermatology and Venereology & 3.5 \\
\hline Medicine I & 16 \\
\hline Neurology and Neurosurgery & 5 \\
\hline Orthopaedics and Traumatology & 5 \\
\hline Otorhinolaryngology & 3.5 \\
\hline Radiology & 4 \\
\hline Surgery I & 15 \\
\hline Therapeutic & 5 \\
\hline \multicolumn{2}{|l|}{ Year V } \\
\hline Anesthesia & 3.5 \\
\hline Legal Medicine & 3.5 \\
\hline Medicine ॥ & 13.5 \\
\hline Ophthalmology & 3.5 \\
\hline Obstetrics and Gynecology & 8 \\
\hline Pathological Anatomy & 3.5 \\
\hline Pediatrics I & 8 \\
\hline Psychiatry I & 5 \\
\hline Surgery II & 8 \\
\hline Urology & 3.5 \\
\hline \multicolumn{2}{|l|}{ Year VI } \\
\hline Community Medicine & 6 \\
\hline Medicine III & 16 \\
\hline Obstetrics & 6 \\
\hline Pediatrics II & 7 \\
\hline Psychiatry II & 4 \\
\hline Surgery III & 11 \\
\hline Research Project & 7 \\
\hline Optional I, II & 3 \\
\hline Total ECTS & 180 \\
\hline
\end{tabular}

\section{Abbreviations}

AIC: Akaike information criterion; BIC: Bayesian information criteria; Cl: Confidence interval; ECTS: European Credit Transfer and Accumulation System; ICC: Intraclass correlation coefficient; Log L: Log likelihood; PCV: Proportional change in variance; $\mathrm{SH}: \%$ of study hours allocated in our curriculum to self-study hours

\section{Acknowledgements}

The authors acknowledge all students who participated in this research.

\section{Funding}

None.

\section{Availability of data and materials}

The data used and analyzed during the current study are available from the corresponding author on reasonable request.

\section{Authors' contributions}

$J B, A S, M A F$ and MS designed the study. JB carried out the design research and drafted the manuscript. MS performed the statistical analysis. JB and MS discussed the results and implications and commented on the manuscript at all stages. AS and MAF gave technical support and conceptual advice and critically revised the manuscript. All authors read and approved the final manuscript.

\section{Authors' information}

$J B$ is researcher at the Department of Medical Education and Simulation of the Faculty of Medicine of the University of Porto. She attends the PhD Program in Biomedicine. AS is Director of the Medicine Course and full Professor at the Institute of Biomedical Sciences Abel Salazar of the University of Porto. MAF is Dean and full Professor at the Faculty of Medicine of the University of Porto. MS is researcher and Professor at the Department of Medical Education and Simulation of the Faculty of Medicine of the University of Porto.

\section{Competing interests}

The authors report no financial or non-financial competing interests.

Ethics approval and consent to participate

This study was approved by the Faculty of Medicine of the University of Porto/São João Hospital Ethics Committee. Students' anonymity was ensured and participation in the study was voluntary.

\section{Author details}

'Department of Simulation and Medical Education, Faculty of Medicine of the University of Porto, Al. Prof. Hernâni Monteiro, 4200-319 Porto, Portugal. ${ }^{2}$ Undergraduate Education Department, Institute of Biomedical Sciences Abel Salazar of the University of Porto, Porto, Portugal. ${ }^{3}$ Department of Simulation and Medical Education, Faculty of Medicine of the University of Porto, Porto, Portugal.

Received: 20 February 2016 Accepted: 15 December 2016

Published online: 13 January 2017

\section{References}

1. Pogacnik M, Juznic P, Kosorok-Drobnic M, Pogacnik A, Cestnik V, Kogovsek J, Pestevsek U, Fernandes T. An attempt to estimate students' workload. J vet med educ. 2004;31:255-60.

2. $\quad$ Snelling PC, Lipscomb M, Lockyer L, Yates S, Young P. Time spent studying on a pre-registration nursing programme module: an exploratory study and implications for regulation. Nurse educ today. 2010;30(8):713-9.

3. van Den Hurk M. The relation between self-regulated strategies and individual study time, prepared participation and achievement in a problem-based curriculum. Act learnhigh educ. 2006;7(2):155-69.

4. Chambers E. Work-load and the quality of student learning. Stud high educ 1992;17(2):141-53.

5. Karjalainen A, Alha K, Jutila S. Give me time to think: determining student workload in higher education; has been written as part of the project titled" 5 years, $2^{\circ \prime}$, funded by the ministry of education, 2004-2006. Finland: Oulu University Press; 2006.

6. Van den Hurk $M$, Wolfhagen $H$, Dolmans $D$, Van der Vleuten $C$. The relation between time spent on individual study and academic achievement in a problem-based curriculum. Adv health sci educ. 1998;3(1):43-9.

7. Kember D, Ng S, Tse H, Wong ET, Pomfret M. An examination of the interrelationships between workload, study time, learning approaches and academic outcomes. Stud high educ. 1996;21(3):347-58.

8. Darmody $M$, Smyth $E$, Unger M. Field of study and Students' workload in higher education ireland and austria in comparative perspective. Int j comp sociol. 2008;49(4-5):329-46.

9. Al Kadri HM, Al-Moamary MS, Elzubair M, Magzoub ME, Almutairi A, Roberts C, van der Vleuten $C$. Exploring factors affecting undergraduate medical students' 
study strategies in the clinical years: a qualitative study. Adv health sci educ. 2011;16(5):553-67.

10. Jansen $E$. The influence of the curriculum organization on study progress in higher education. Higher educ. 2004;47(4):411-35.

11. Kerdijk W, Tio RA, Mulder BF, Cohen-Schotanus J. Cumulative assessment: strategic choices to influence students' study effort. BMC med educ. 2013;13(1):1.

12. Lockwood F. Estimating student workload: implications for quality learning. Staff educ dev int. 1999;3(3):281-9.

13. Chambers E. Assessing learner workload. In: Lockwood F, (Ed). Materials production in open and distance learning. London: Paul Chapman Publishing; 1994. p. 103-11.

14. Wilkinson TJ, Wells JE, Bushnell JA. Medical student characteristics associated with time in study: is spending more time always a good thing? Med teach. 2007;29(2-3):106-10.

15. Newble D, Entwistle N. Learning styles and approaches: implications for medical education. Med educ. 1986;20(3):162-75.

16. Kusurkar RA, Croiset G, Galindo-Garré F, Ten Cate O. Motivational profiles of medical students: association with study effort, academic performance and exhaustion. BMC med educ. 2013;13(1):1.

17. Seabrook MA. Clinical students' initial reports of the educational climate in a single medical school. Med educ. 2004;38(6):659-69.

18. Van Hell EA, Kuks J, Schönrock-Adema J, Van Lohuizen MT, Cohen-Schotanus J. Transition to clinical training: influence of pre-clinical knowledge and skills, and consequences for clinical performance. Med educ. 2008:42(8):830-7.

19. Young JQ, Van Merrienboer J, Durning S, Ten Cate O. Cognitive load theory: implications for medical education: AMEE guide no. 86. Med teach. 2014;36(5):371-84

20. Duvivier RJ, van Geel K, van Dalen J, Scherpbier AJ, van der Vleuten CP. Learning physical examination skills outside timetabled training sessions: what happens and why? Adv health sci educ. 2012;17(3):339-55.

21. Nielsen DG, Jensen SL, O'Neill L. Clinical assessment of transthoracic echocardiography skills: a generalizability study. BMC med educ. 2015;15(1):9.

22. Stawski RS. Multilevel analysis: an introduction to basic and advanced multilevel modeling. Struct equ model multidiscip j. 2013;20(3):541-50

23. Mueller S, Weichert N, Stoecklein V, Hammitzsch A, Pascuito G, Krug C, Holzer M, Pfeiffer M, Siebeck M, Schmidmaier R. Evaluation of effectiveness of instruction and study habits in two consecutive clinical semesters of the medical curriculum munich (MeCuM) reveals the need for more time for self study and higher frequency of assessment. BMC med educ. 2011;11(1):1.

24. Dolmans D, Wolfhagen H, Essed G, Scherpbier A, Van Der Vleuten C. Students' perceptions of time spent during clinical rotations. Med teach. 2001;23(5):471-5.

25. Philip J, Whitten CW, Johnston WE. Independent study and performance on the anesthesiology in-training examination. J clin anesth. 2006;18(6):471-3.

26. Worley P, Prideaux D, Strasser R, March R, Worley E. What do medical students actually do on clinical rotations? Med teach. 2004;26(7):594-8.

27. Gijselaers WH, Schmidt HG. Effects of quantity of instruction on time spent on learning and achievement. Educ res eval. 1995;1(2):183-201.

28. Van Hell EA, Kuks J, Cohen-Schotanus J. Time spent on clerkship activities by students in relation to their perceptions of learning environment quality. Med educ. 2009;43(7):674-9.

\section{Submit your next manuscript to BioMed Central and we will help you at every step:}

- We accept pre-submission inquiries

- Our selector tool helps you to find the most relevant journal

- We provide round the clock customer support

- Convenient online submission

- Thorough peer review

- Inclusion in PubMed and all major indexing services

- Maximum visibility for your research

Submit your manuscript at www.biomedcentral.com/submit

CBiomed Central 